\title{
Evaluation of Drug Utilization and Analysis of Anti- Epileptic Drugs at Tertiary Care Teaching Hospital
}

\author{
Jincy George, Julia Jose, Divya Ashok Kulkarni, Ramesh Rajesh Pol ${ }^{1}$ Mallappa Hanamantappa \\ Shalavadi, Chandrashekhar Venkaraddi Mangannavar
}

Department of Pharmacy Practice, Hanagal Shri Kumerashwar College of Pharmacy, Bagalkot, Karnataka, INDIA

${ }^{1}$ Department of Pediatrics, S.N.Medical College and H S K hospital and Research center, bagalkot-587101

\begin{abstract}
Background: Epilepsy has been considered as a public health problem by WHO and ILAE. It was felt that there remains considerable scope for the development of better epilepsy services in a developing country like India. Hence we sought to evaluate the drug utilization of antiepileptic drugs. Aim: The study was designed to evaluate the drug utilization of anti epileptic drugs in in-patient admission of medicine and pediatric departments at tertiary care teaching hospital. Methods: The data was obtained prospectively from 132 patients with antiepileptic drug over a period of 6 months. The utilization was assessed based on age, seizure type, therapy, newer and conventional AEDs and rationality of prescriptions. Results: AEDs are highly prescribed for an age group of 0-2 years in the study. AEDs are highly prescribed as monotherapy in $62.12 \%$ of the patients. In the study $51.5 \%$ of AED were prescribed alone and $40.62 \%$ of AED with add-on therapy of benzodiazepine and found statistically significant $(P<0.005)$. Assessment of rationality was done as per ILAE and IAP guidelines of which $64 \%$ and $75.7 \%$ were found to be rational respectively. Conclusion: In the study, conventional AEDs are used as monotherapy was more effective in terms of reduction of seizures, as they are available at low costs and are more affordable than the newer drugs and polytherapy. The study concludes the effective use of benzodiazepines along with AED. Due to the lack of specific guidelines for the usage of AED in India, the rationality in the prescription is variable and poor.
\end{abstract}

Key words: Antiepileptic, Drug utilization, Rationality, Polytherapy, Prescription pattern.

\section{INTRODUCTION}

Epilepsy is a chronic neurological disorder characterized by recurrent unprovoked seizures. Epilepsy is affecting about 50 million people worldwide. ${ }^{1}$ In India, the prevalence rate of epilepsy ranges between 4.15 and 7.03 per 1000 population. ${ }^{2}$ Most people with epilepsy are being diagnosed and treated by non-specialists at different health care levels. Therefore, in most of such situations, epilepsy management can be suboptimal. Moreover, it was felt that there remains considerable scope for the development of better epilepsy services in a developing country like India. ${ }^{1}$

General approaches for epilepsy management involves identification of goals and development of care plan. ${ }^{3}$ The overall goal of antiepileptic therapy is to prevent seizures and avoid untoward side effects with the regimen that is convenient and easy to follow.
The choice of most appropriate antiepileptic drug (AED) depends on classification of seizures and age of patient. ${ }^{4}$ Monotherapy is normally the first line of treatment, as it has less drug interactions and side effects, lower cost, better tolerability, medication adherence, and quality of life. Despite advances in the treatment of epilepsy, $30-40 \%$ of patients remain uncontrolled on a single AED. The choice of optimal polytherapy possess difficulty for several reasons. ${ }^{5}$

In recent years, new AEDs that combines high efficacy with a low incidence of adverse effects have been developed (gabapentin, lamotrigine, levetiracetam, oxcarbazepine, tiagabine, topiramate, zonisamide). These newer AEDs are used as an adjunct to conventional AEDs in children with intractable epilepsy. Newer drugs are more efficacious and have a better safety as compared
DOI: 10.5530/ijopp.9.3.10

Address for correspondence:

Dr. Chandrashekhar Venkaraddi Mangannavar, HOD,

Department of Pharmacy Practice, H.S.K College of Pharmacy, Bagalkot,

Karnataka, INDIA.

Phone no: 09880298342

Email: chandupharm@yahoo. com

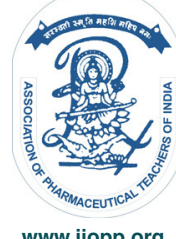

www.ijopp.org 
to conventional AED. However, caution must be exercised for possible drug interactions with conventional AEDs before using them as an adjunct. Moreover, many of these newer AEDs have been recently launched in Indian market and costs of some of them are largely prohibitive. $^{6}$

The anticonvulsant effect of benzodiazepine finds their greatest clinical use in acute control of seizures. Benzodiazepines are undoubtedly potent anticonvulsant on acute administration, but their use in long term treatment of epilepsy is limited by the development of tolerance to the anticonvulsant effect and by side effects such as sedation and psychomotor slowing. They are usually considered as an adjunct to standard drugs where this have failed to give acceptable control. ${ }^{7}$

Clinical pharmacy services in this study provided by pharmacist is an attempt to promote rational drug therapy by assessing the current pattern of prescription in the country based on the age, mono/polytherapy, use of newer AED`s and combination use of benzodiazepines along with AED`s. It can ensure the rational use of medication and improve patient compliance with medication. ${ }^{8}$ About $90 \%$ of epileptic patients in developing countries are not receiving appropriate treatment due to the cultural attitude, lack of prioritization, poor health care system, economic problems etc. Pharmacist in hospitals can initiate changes to drug therapy for patient management to promote rational drug use. Hence, our study was designed to analyze the prescribing pattern and rationality in prescriptions according to national and international guidelines in tertiary care teaching hospital of India.

\section{MATERIAL AND METHODS}

It was a prospective study of six months duration (November to April 2014-15) and designed to evaluate the drug utilization and rationality of AED prescription in 132 inpatients of General Medicine and Pediatric departments of a tertiary care teaching hospital in India. The study was conducted by taking approval from Institutional Ethics Committee. The subjects included were patients of either sex of any age undergoing treatment in medicine and pediatric departments in the hospital who were on AED prescription. Patients receiving treatment on outpatient basis and pregnant women were excluded from the study. Patients who met the study protocol criteria were included and the required data were collected from the patient case file on a daily basis. In the present study, the rationality assessment of data had done with the help of standard clinical guidelines for epileptic therapy and management via International league against epilepsy (ILAE) guidelines, Indian pediatric association guidelines (IPA) -National guidelines and NICE clinical guidelines-International guidelines.

\section{STATESTICAL ANALYSIS}

Data analysis was done using the statistical program Prism 0.5 software. Categorical data was presented as percentages. Differences between means of groups were compared using ANOVA and Chi square test. A $p$-value less than 0.05 were considered as statistically significant

\section{RESULTS}

\section{Socio-demographic details of subjects}

A total of 132 subjects were assessed for drug utilization of AED`s for the 6 months study period. The socio-demographic details of study participants are represented in Table 1 . The results show there is a male predominance in AEDs usage. The AEDs are prescribed highly in the age group of 2-11 years. The occurrence of seizures depicts a highest percentage of generalized seizures (51\%) than the partial and other types. The study shows the hospital admission of seizures are more for new onset seizures (56.36\%) than recurrent or known case of seizures (established). The etiological basis shows most of the seizures occurred due to of secondary causes $(58.18 \%)$.

\section{Categorization of different patients prescribed with AED}

Number of AED prescribed per patient during the study period a total of 246 AEDs were prescribed for 132 patients who correspond to an average of $1.86 \%$ AEDs prescribed per patient. Overall AED utilization the overall prescription of AED as monotherapy, dual therapy, three drug therapy, four drug therapy, five drug therapy are reported in Figure 1.

\section{Comparison of mono and poly therapy}

Out of 132 patients monotherapy (62.12\%) was found to be superior to polytherapy $(37.87 \%)$ in controlling seizures. There was a significant difference found between monotherapy and polytherapy in terms of age group $(\mathrm{p}=<0.000)$. This data is shown in Table 2 .

\section{Most frequent AED monotherapy and combination therapy}

In this study phenytoin was the most frequently prescribed AED monotherapy followed by sodium valproate. The most used combination drugs were sodium valproate with lorazepam and leviteracetam followed by combination with phenytoin. The data is reported in Figure 2 and Figure 3.

Indian Journal of Pharmacy Practice, Vol 9, Issue 3, Jul-Sep, 2016 


\section{Seizure treated with AED and BZD}

Most patients were treated with AED only with 51.5\% as compared to the AED with BZD groups and BZD only. Among the AED with BZD groups, 1 AED with BZD, 2 AED with BZD, 3 AED with BZD, 4 AED with BZD, 5 AED with BZD are 19.69\%, 12.12\%, $6.8 \%, 0.5 \%, 1.51 \%$ respectively. There is a significant difference between $(\mathrm{P}<0.005)$ AED used alone $\mathrm{v} / \mathrm{s}$ BZD used alone. These details are presented in Table 3 .

\section{Utilization pattern of AED as older, newer and older with newer AEDs}

In the present study, older AEDs are more 80.3\% frequently used to treat seizures followed by older with newer AED combination $17.47 \%$ and newer AED used alone $3.7 \%$. Results are shown in Table 4. In this study older drugs were commonly prescribed than newer drugs and found significant difference in $0-5$ years $(p<0.0001)$, 6-10 years ( $p=0.0252), 11-18$ years $(p<0.0001),>18$ years $(p<0.0001)$. Some of the few prescriptions had preferred older with newer drug combination therapy.

\section{Rationality assessment of AED prescriptions}

Out of total 246 prescriptions, 187 prescriptions were analyzed for rationality assessment. In which only 125 prescriptions were selected for rationality assessment as per the global standard ILAE (International League Against Epilepsy) guidelines ( $>18$ years) of which $80(64 \%)$ were found to be rational and $45(36 \%)$ of prescription were irrational. The IAP (Indian Association of Pediatrics) guidelines ( $<18$ years) was used for assessing 140 prescriptions, in which $106(75.7 \%)$ were found to be rational and $34(24.48 \%)$ were irrational. Similarly by NICE (National Institute for Health and Care Excellence) guidelines of United Kingdom 151 prescription were subjected for rationality review, only $84(55.62 \%)$ of prescriptions were found rational and 67 (44.33\%) of prescriptions were irrational. The details of rationality of AED prescriptions are presented in Figure 4.

\section{DISCUSSION}

A total of 132 cases from which 246 prescriptions with AED have been analyzed for demographic variables, characteristics of seizures, classification of seizures and used to assess the drug utilization and rationality of AED in the in-patient hospital settings of medicine and pediatric department. According to literature the incidence of epilepsy has a bimodal distribution with a peak in the first decade and second peak in the elderly., ${ }^{910}$ In the present study, the peak was observed at the age group of $0-11$ years $(49.12 \%)$ followed by younger age group $12-30$ years $(24.99 \%)$.In our study we found the males $(65.90 \%)$ to be almost two folds greater than females
(34.09\%) on AED prescription. Similar to reports from other Asian countries there was slightly male predominance. ${ }^{11}$ In India, less number of females may be due to higher illiteracy, social stigma and the need for the male relative to concern and accompany the female for hospital visit. The probable reason for the missing peak in the older age group in many Asian countries is due to the fact that most of the population are younger compared to number of elderly which is true in Indian context also. ${ }^{12,13}$

There was large number of generalized seizures (51\%) among our study subjects followed by partial seizures $(21 \%)$. Our studies were similar to the reports from most of the Asian countries, ${ }^{14}$ where generalized seizures ranges from $50-60 \%$ and partial seizures from $31-50 \%$. Often it is quite difficult to compare results of these studies due to lack of application of standardized classification system in epilepsy research in Asia and lack of imaging and EEG studies, which probably had led to predominance of generalization in most of the studies. Most of the epileptic patients were effectively managed with conventional AEDs like phenytoin, carbamazepine, valproic acid and phenobarbitone as observed in the earlier studies. ${ }^{15,16}$ The highly used AEDs among the study population were phenytoin (19.51\%) and valproic acid $(17.88 \%)$, both were mainly used for generalized seizures. For partial seizures the highly used AEDs were valproic acid followed by phenytoin, carbamazepine and lorazepam. Phenobarbitone was prescribed for both generalized and partial seizures.

Monotherapy was practiced in $62.12 \%$ of our patient, which is similar in many studies with its many advantages. ${ }^{16,17}$ Nevertheless, multiple drug therapies are unavoidable in some patients (37.87\%), even though polypharmacy adversely affect the quality of life. In $32(24.24 \%)$ patients, seizures were managed with dual therapy. The commonly prescribed AED combination was phenytoin/valproic acid with levetiracetam and phenytoin with phenobarbitone, as their combinations are available at low cost and are more affordable. Valproic acid with levetiracetam and valproic acid with lorazepam are our most commonly used combinations. There was a statistically significant difference $(p<0.000)$ found between monotherapy and polytherapy, this indicates that the conventionally used monotherapy was more effective in terms of reduction of seizures. Nevertheless, polytherapy is unavoidable in some patients, though it adversely affects the quality of life and increases the chances of drug related problems. This was observed in present study. The newer AEDs like vigabatrin, nitrazepam and zonisamide were used in few cases with old AED drugs (17.47\%). 
Table 1: Socio-demographic details of the epileptic patients

Socio-demographic parameters

\begin{tabular}{|c|c|c|}
\hline Gender & No. of patients & Percentage \\
\hline Male & 87 & $65.90 \%$ \\
\hline Female & 45 & $34.09 \%$ \\
\hline Age & No. of patients & Percentage \\
\hline 0-27 days & 09 & $6.81 \%$ \\
\hline 28 days-23 months & 26 & $19.69 \%$ \\
\hline $2-11 \mathrm{yr}$ & 30 & $22.72 \%$ \\
\hline $12-18 \mathrm{yr}$ & 11 & $8.33 \%$ \\
\hline $18-30 \mathrm{yr}$ & 22 & $16.66 \%$ \\
\hline $31-45 \mathrm{yr}$ & 15 & $11.36 \%$ \\
\hline $40-60 \mathrm{yr}$ & 09 & $6.81 \%$ \\
\hline $61-75 \mathrm{yr}$ & 06 & $4.54 \%$ \\
\hline$>75 \mathrm{yr}$ & 04 & $3.03 \%$ \\
\hline \multicolumn{3}{|c|}{ Categorization of different patients prescribed with AED } \\
\hline \multicolumn{3}{|c|}{ 1. Epileptic patients } \\
\hline Generalized seizures & No. of patients & Percentage \\
\hline Tonic seizures & 12 & $9.09 \%$ \\
\hline Clonic seizures & 20 & $15.15 \%$ \\
\hline Tonic clonic seizures & 31 & $23.48 \%$ \\
\hline Myoclonic seizures & 04 & $3.03 \%$ \\
\hline Partial seizures & No. of patients & Percentage \\
\hline Simple partial seizures & 12 & $9.09 \%$ \\
\hline Complex partial seizures & 08 & $6.06 \%$ \\
\hline Partial seizures with secondary generalization & 08 & $6.06 \%$ \\
\hline Seizures due to secondary causes & No. of patients & Percentage \\
\hline Diseases & 12 & $9.09 \%$ \\
\hline Toxicity & 03 & $2.27 \%$ \\
\hline \multicolumn{3}{|c|}{ 2. Other patients } \\
\hline $\begin{array}{c}\text { (prophylactic treatment, neonatal birth asphyxia, } \\
\text { psychotic disorders) }\end{array}$ & 22 & $16.66 \%$ \\
\hline \multicolumn{3}{|c|}{ Characteristics of seizure } \\
\hline 1. Type of onset & No. of patients & Percentage \\
\hline Established & 16 & $14.54 \%$ \\
\hline Recurrent & 32 & $29.09 \%$ \\
\hline New onset & 62 & $56.36 \%$ \\
\hline 2. Etiology & No. of patients & Percentage \\
\hline Primary causes & 46 & $41.81 \%$ \\
\hline Secondary causes & 64 & $58.18 \%$ \\
\hline
\end{tabular}

\section{Table 2: Comparison of mono and polytherapy according to age.}

\begin{tabular}{|c|c|c|c|c|c|c|c|}
\hline \multirow{2}{*}{$\begin{array}{c}\text { Types of AED } \\
\text { therapy }\end{array}$} & \multicolumn{4}{|c|}{ No. of patients according to age } & \multirow{2}{*}{ Total (\%) } & \multirow{2}{*}{$\begin{array}{l}\text { Chi square } \\
\text { value }\end{array}$} & \multirow{2}{*}{$p$ value } \\
\hline & $0-5 \mathrm{yr}$ & $6-10 \mathrm{yr}$ & $11-18 \mathrm{yr}$ & $>18 \mathrm{yr}$ & & & \\
\hline Monotherapy & $28(34.14 \%)$ & $01(1.21 \%)$ & $07(8.53 \%)$ & $46(56.09 \%)$ & $82(62.12 \%)$ & & \\
\hline Polytherapy & $30(60 \%)$ & $05(10 \%)$ & $05(10 \%)$ & $10(20 \%)$ & $50(37.87 \%)$ & 19.60 & 0.000 \\
\hline Total & 58 & 06 & 12 & 56 & 132 & & \\
\hline
\end{tabular}




\begin{tabular}{|c|c|c|c|c|c|c|}
\hline \multirow{2}{*}{ Treatment given } & \multicolumn{4}{|c|}{ According to age } & \multirow{2}{*}{ Total } & \multirow{2}{*}{$p$ value } \\
\hline & $0-5 \mathrm{yr}$ & $6-10 \mathrm{yr}$ & $11-18 \mathrm{yr}$ & $>18 \mathrm{yr}$ & & \\
\hline AED only & 18 & 07 & 00 & 43 & $68(51.51 \%)$ & \multirow{3}{*}{0.005} \\
\hline BZD only & 08 & 00 & 00 & 02 & $10(7.57 \%)$ & \\
\hline Total & 24 & 07 & 00 & 45 & $78(59.08 \%)$ & \\
\hline BZD+1AED & 14 & 02 & 03 & 07 & $26(19.69 \%)$ & \multirow{6}{*}{0.0001} \\
\hline$B Z D+2 A E D$ & 10 & 02 & 01 & 03 & $16(12.12 \%)$ & \\
\hline BZD+3AED & 06 & 02 & 01 & 00 & $09(6.8 \%)$ & \\
\hline$B Z D+4 A E D$ & 01 & 00 & 00 & 00 & $01(0.5 \%)$ & \\
\hline$B Z D+5 A E D$ & 01 & 00 & 00 & 01 & $02(1.51 \%)$ & \\
\hline Total & 32 & 06 & 05 & 11 & $52(40.62 \%)$ & \\
\hline
\end{tabular}

\begin{tabular}{|c|c|c|c|c|}
\hline \multirow{2}{*}{ Age } & \multicolumn{3}{|c|}{ Types of AED } & \multirow{2}{*}{$\begin{array}{l}\text { ANOVA } \\
p \text { value }\end{array}$} \\
\hline & Older drugs & Newer drugs & Older+newer drugs & \\
\hline $0-5 y r$ & 43 & 01 & 14 & 0.0252 \\
\hline $6-10 y r$ & 04 & 00 & 02 & 0.0020 \\
\hline $11-18 \mathrm{yr}$ & 10 & 00 & 02 & 0.0001 \\
\hline$>18 \mathrm{yr}$ & 49 & 02 & 05 & 0.0001 \\
\hline Total & $106(80.3 \%)$ & $03(2.27 \%)$ & $23(17.42)$ & \\
\hline
\end{tabular}

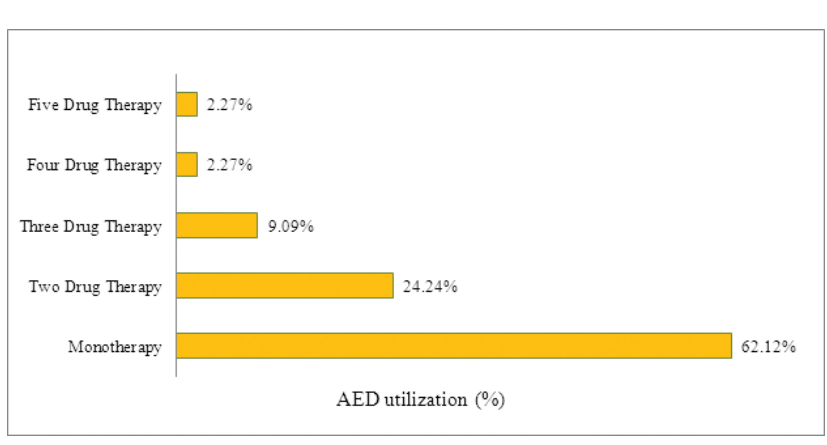

Figure 1: Overall AED utilization

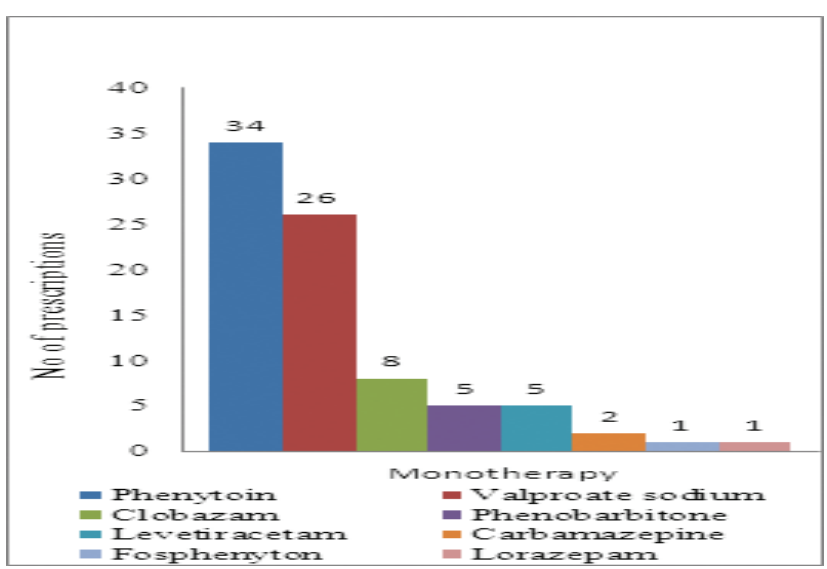

Figure 2: Monotherapy drug distribution

Indian Journal of Pharmacy Practice, Vol 9, Issue 3, Jul-Sep, 2016

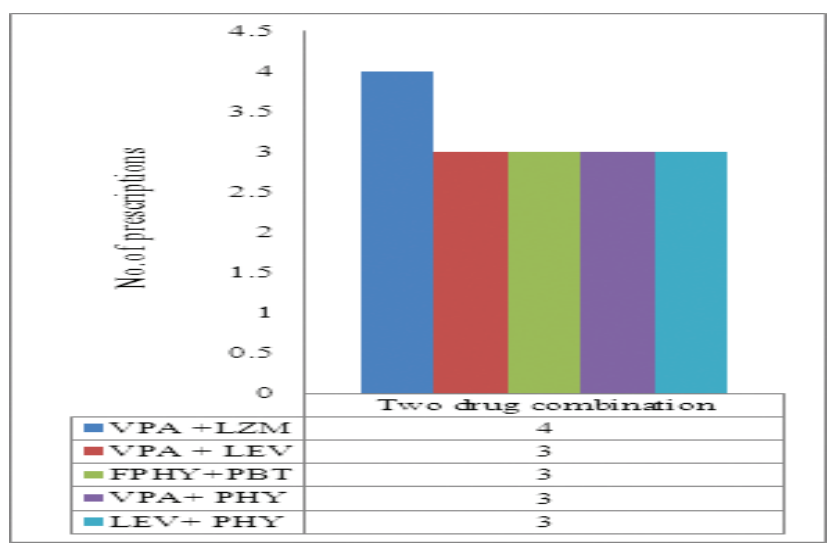

Figure 3: dual therapy drug distribution

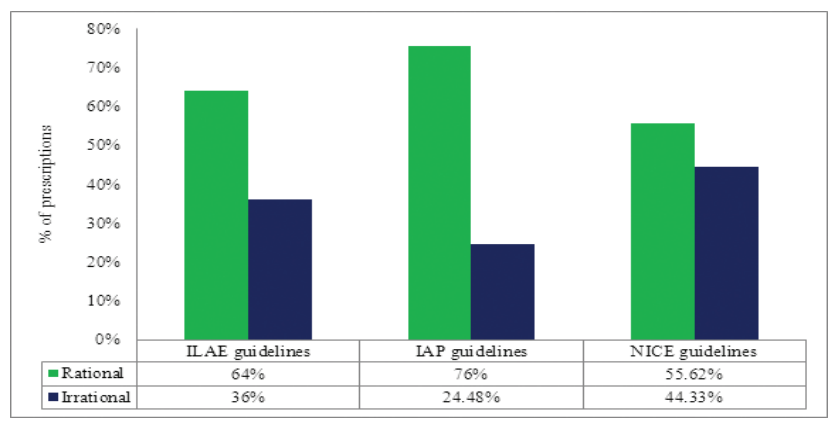

Figure 4: Assessment of Rationality of AED prescribed for epileptic patients 
In our study $51.5 \%$ of AED alone were prescribed and $40.62 \%$ of AED with add-on therapy of benzodiazepine prescriptions were observed. AED versus benzodiazepine prescription, AED alone prescription are more commonly $(51.5 \%)$ found statistically significant $(\mathrm{P}<0.005)$ as compared to benzodiazepine usage for treatment of epilepsy. Hence there is always a pattern of adding BZD with AED in the study.

Assessment of rationality was done as per ILAE guidelines and IAP (Indian Association of Pediatrics) guidelines. According to ILAE guidelines, 64\% prescriptions were rational and $36 \%$ of prescriptions were irrational with respect to selection of drug, selection of right dose and right patient. As per IAP guidelines $75.7 \%$ of prescription was found rational and $24.48 \%$ of prescriptions were found irrational. Similarly, as per International Guidelines of UK, NICE guidelines, $55.62 \%$ were rational and $44.33 \%$ were irrational prescription. This indicates that most of the pediatricians in India follow the IAP guidelines whereas for the adults due to the lack of standard guidelines in India, irrational prescriptions are more found in prescriptions.

\section{CONCLUSION}

In conclusion, our study on AED usage in South Indian tertiary care teaching hospital shows that conventional AEDs are used as monotherapy was more effective in terms of reduction of seizures, as they are available at low costs and are more affordable than the newer drugs and polytherapy. Phenytoin and valproic acids were the most commonly used monotherapy followed by sodium valproate with levetiracetam/lorazepam and phenytoin with phenobarbitone/sodium valproate in combination therapy. The study concludes the effective use of benzodiazepines along with AED. Due to the lack of specific guidelines for the usage of AED in India, the rationality in the prescription is variable and poor.

\section{ACKNOWLEDGEMENT}

The authors would like to thank Dr. I.S. Muchchandi, Principal, H.S.K College of Pharmacy, Bagalkot. I also thank Principal, SN Medical College and H.S.K Hospital, Bagalkot and all healthcare professionals of General Medicine and Pediatric department of H.S.K. Hospital and Research Center, Bagalkot for their constant support and guidance.

\section{CONFLICT OF INTEREST}

The authors declare no conflict of interest.

\section{ABBREVIATION USED}

AED: Antiepileptic drug

BZD: Benzodiazepines

ILAE: International League Against Epilepsy

IPA: Indian Association of Pediatrics

NICE: National Institute for Health and Care Excellence)

UK: United Kingdom

\section{REFERENCES}

1. Mrinal K, Dhiman D. Indian guidelines on epilepsy. The association of Physician of India 2012. URL: www.apiindia.org/medicine_update_2013/chap116.pdf

2. Sridharan R. Epidemiology of epilepsy. Current Science. 2002;82(6):664-7.

3. Mallik A, Nupur A. A descriptive analysis of drug treatment patterns and burden of illness for pediatric patients diagnosed with partial-onset seizures in the USA. Pediatric Health Medicine and Therapeutics. 2011;(2):275-84

4. Kumaran AK, Palanisami S, Rajasekharan A. A study on drug use evaluation of anti-epileptics at a multi-specialty tertiary care teaching hospital. International Journal of Pharm Tech Research. 2009;1(4):1541-7.

5. Kwan P, Brodie MJ. Combination therapy in epilepsy: when and what to use. Drugs. 2006;66(14):1817-29.

6. Aneja S, Sharma S. Newer Anti-epileptic Drugs. Indian Pediatrics. 2013;50(11):1033-40.

7. Eadie MJ. Anti-convulsant drugs: an update. Drugs. 1984;27(4): 328-63.

8. Charles $\mathrm{BH}$, Linda MS. Opportunities responsibility in pharmaceutical care. American Journal of Hospital Pharmacy. 1990;47(3):533-4.

9. Caprio A, Hauser WA. Epilepsy in the developing world. Current Neurology and Neuroscience Reports. 2009;9(4):319-26.

10. Hanssen Y, Dxlue D, Al Balushi K, Al Hashar A, Al Zakwani I. Drug utilisation pattern of antiepileptic drugs: A pharmacoepidemiologic study in Oman. Journal of clinical pharmacy and therapeutics. 2007;27(5):357-64.

11. Lim SH, Tan EK. Pattern of anti epileptic drug usage in tertiary referral hospital in Singapore. Neurological Journal of South East Asia. 1997;2(24):77-85.

12. Mac TL, Tan DS, Quet F, Odermatt P, Preux PM, Tan CT. Epidemiology, etiology and clinical management of epilepsy in Asia: a systematic review. The Lancet Neurology. 2007;6(6):533-543.

13. Singhal BS. Neurology in developing countries: A population prespective. Archives of neurology. 1998;55(7):1019-21.

14. Radhakrishnan K, Pandian JD, Santhoshkumar T, Thomas SV, Deetha TD, Sarma PS. Prevalence, knowledge, attitude and practice of epilepsy in Kerala, South India. Epilepsia. 2000;41(8):1027-35.

15. Kariyawasm SH, Bandara N, Koralaguma A, Senenayake S. Challenging epilepsy with antiepileptic pharmacotherapy in a tertiary care teaching hospital in Sri Lanka. Neurology India. 2004;52(2):233-7.

16. Huying F, Klimpre S, Werhan KJ. Anti-epileptic drug use in nursing home residents: A cross sectional, regional study. Seizure. 2006;15(3):194-7.

17. Christensen J, Kjeldsen MJ, Andersen H, Frisis ML. Gender differences in epilepsy. Epilepsia. 2005;46(6);456-60. 